\title{
ASSESSMENT OF ORIGINAL DENTAL DIAGNOSTIC PROGRAM IN THE OPINION OF DENTISTS
}

\author{
Paweł Łabno ${ }^{1}$, Aleksandra Łabno', Renata Chałas ${ }^{2}$ \\ 'Dental Private Practice, Gorlice, Poland \\ ${ }^{2}$ Department of Oral Medicine, Medical University of Lublin, Poland
}

\begin{abstract}
INTRODUCTION: An increase of information, especially in the field of medicine and dentistry, has led to the development of areas related to diagnosis and treatment. Rapid pace of development means that doctors around the world want to practice evidence-based medicine with the latest research results. The condition for successful treatment is the correct diagnosis.

ОвJеCTIVEs: The aim of the study was to develop a computer algorithm for a dental office and evaluate dentists' opinions about the computer algorithm created by the author for dental diagnostics.

MATERIAL AND METHODS: The research was carried out in a group of dentists in a private dentist's office. Dentists performed treatment according to their well-known standards (group 1), then according to proposed algorithm (group 2), and filled a questionnaire comparing both methods.

RESULTS: Algorithm evaluation was performed by dentists on a group of 300 treated patients, with 156 women (52\%) and 144 men (48\%), and the average age was 34.13 years. For the majority of conducted examinations (88.67, 99\%), dentists stated that the algorithm used during an interview and examination fulfilled their expectations. Statistically significantly higher time values needed to conduct medical interview in accordance with the proposed study algorithm were found in men compared to women $(p<0.05)$.

Conclusions: The application of the proposed diagnostic algorithm was positively received by dental doctors. Most dentists considered working using the algorithm as facilitating the communication with the patient and increasing his participation in the treatment process. The conducted research indicated the need for a holistic approach to the patient, raising awareness of the impact of systemic diseases on the state of oral health.
\end{abstract}

KEY WORDS: dentistry, evidence-based dentistry, algorithm, diagnostics, telemedicine.

\section{INTRODUCTION}

The increase of information, especially in medicine and dentistry, has led to the development of fields related to diagnosis and treatment. It is currently claimed that the total amount of medical knowledge doubles every 10-15 years. Such an increase and detailed specializations mean that a general practicing physician or den- tist may have difficulty reading all the latest publications. In addition, finding clinically relevant information can be another problem. On the other hand, the rapid pace of medical development means that doctors around the world want to practice the latest research results, but those based on scientific evidences [1].

Evidence-based medicine (EBM), a branch of evidence or scientific data-based medicine, has been developed in the 1980s in Canada. The precursor of its crea-

\section{JOURNAL OF STOMATOLOGY CZASOPISMO STOMATOLOGICZNE

Address for correspondence: Dr. Paweł Łabno, Dental Private Practice, 95 Tadeusza Kościuszki Str., 38-300 Gorlice, Poland, e-mail: stomatologialabno@gmail.com

ReCEIVED: 16.04 .2020 • ACCEPTED: 14.08.2020 • Published: 30.10 .2020 
tion was clinical epidemiology, a discipline dealing with issues of medical experiments and assessment of the reliability of clinical trials. The pioneers of evidence-based medicine were David L. Sackett and Gordon Guyatt, who described the EBM as careful, unambiguous, and sensible use of scientific evidence, when making treatment decisions for patients. In accordance with the evidence-based medicine, the best therapeutic result can be achieved in medical procedures at the current level of knowledge. By accessing the latest high-quality scientific research, one can assess the risks and benefits of using different treatments, which facilitates a final decision making about patient's care. It should also be considered that existing treatment options may be questioned [1-3].

Due to the fact that the evidence-based medicine also considers patients' expectations, despite credible guidelines, the physician should consider the patient's needs when deciding on diagnostic or therapeutic method. Disregarding these factors, especially the patient's clinical situation and preferences, may lead to failure of benefits from using guidelines [4].

Modern information technology (IT) create real opportunities to combine clinical practice, research results, and an education system using the evidence-based medicine. Many publications show high effectiveness of treatment while making decisions based on the EBM. However, the most time-consuming is the development and publication of articles and the lack of financing of organizations publishing the latest research results as well as the lack of legal possibilities to use figures, photos, charts, and drawings from other publications. It should be remembered, however, that continuous updating of practical knowledge should allow differentiation of hard evidence from advertising, suppositions from certainty, and scientific evidence from personal beliefs $[5,6]$.

In recent years, a new term called "evidence-based dentistry" (EBD) has appeared in scientific journals. Instead of individual treatment of each case based on the experience and clinical knowledge of the dentist, the EBD requires analytical and statistical approach. Despite a huge development of dental knowledge, including new materials, high number of publications on disease prevention, and new methods of diagnosis and treatment, dentists have a problem with the implementation of this knowledge into clinical practice. Significant differences in the methods of treating the same clinical case depend on many factors, such as private and state office, financing method, doctor's experience, quality of materials used, and a motivation to improve individual medical knowledge. Researches indicate that dentists, who attempt to use an EBM approach in the treatment based on information found online, have not been successful in their office due to lack of clinical guidance on proper management. Therefore, the use of evidence-based dentistry in clinical practice (evidence-based practice - EBP) allows dental doctors to support their clinical decision making (evidence-based decision making - EBDM) $[7,8]$.
The use of scientific evidence in everyday practice requires doctors to read articles, participate in courses, and search through electronic databases in response to their own clinical questions. However, scientific research indicates that the most common source of knowledge, apart from textbooks from the time of study, are other doctors, and that a change in decision about the treatment carried out so far in a patient is often made based on a trust in another specialists' opinion. At the same time, the conclusions of the study indicate that the longer period from doctors' graduation, the greater the lack of knowledge on modern treatment methods, procedures, and diagnostic techniques [9].

The American Dental Association's information indicates the need to educate students and dentists towards a comprehensive approach to patient, critical thinking, evidence-based treatment, seeking information on current clinical problems, continuous analysis of patient's treatment results to improve the therapy used, and assessing the credibility of scientific literature allowing decision making [10].

It should be remembered that evidence-based dentistry is not a list of ready-to-use prescriptions for every clinical case, which could be found in the dental office, but it is an auxiliary tool that facilitates correct clinical decisions, which are customized to an unique individual. Therefore, it is necessary to make a proper diagnosis, find high-quality scientific research on a given clinical case, understand the psychology of patient, his expectations, emotions, and financial possibilities [11].

Currently used telemedicine systems are used for 1 . Information purposes: registration of visits via the Internet, checking the results of online examinations, access to medical information websites, telephone consultants, providing information by lower level personnel; 2. Preventive functions: remote monitoring of health (measurement of heart rate, pressure, weight, glucose and hemoglobin levels) and education of healthy patients; 3. Therapeutic purposes: electronic documentation, conducting operations at a distance, X-ray sending, cone beam computed tomography, electrocardiography, magnetic resonance imaging, and ultrasound images; 4. Educational and researching functions: organizing videoconferences for specialists in various fields of medicine as well as for doctors and patients, virtual teams consisting of health professionals, cooperating and exchanging information about patients in order to improve dental skills and quality of services, clinical supervision of specialist during surgery similar to Venetian mirror, examining, and supervising young doctors [12].

Despite such a large and wide access to databases and telemedicine capabilities, no doctor has the full knowledge and is not able to follow the results of all the latest studies, treatment options, or modifications of procedures. Dentistry, like other medical fields, should also be based on evidence as well as the most current knowledge and results of independent research. The ideal solution 
for every dentist would be a cooperation with an individual (personal) advisor, who has both the most current theoretical knowledge in the field of scientific publications and an experienced practitioner, who is able to combine procedures from all fields of dentistry, enabling a holistic view on the patient. This solution is obviously not possible at the moment, but it can be slightly easier for dentists to access the latest knowledge and procedures used in the most frequently diagnosed medical problems in their clinical practice [13].

\section{OBJECTIVES}

The reason for successful treatment is the correct diagnosis. Diagnostics is the science of diagnosing the diseases based on the analysis of symptoms and test results. As in the other fields of science, computers facilitate and accelerate the work of a doctor. In dentistry, it is also possible to use software based on data from a database of diseases to analyze information collected during an interview and research for differential diagnosis.

The aim of the study was to evaluate the practical use of a computer algorithm (original program) for dental diagnostics, and to analyze the relationship between an examination using a computer program and dentists' subjective assessment.

\section{MATERIAL AND METHODS}

The research included a group of dentists in a private dentist's office. Among the respondents, as a method of collecting primary information by obtaining answers to previously prepared questions, a questionnaire was used. The research was approved by bioethics commit- tee of the Medical University of Lublin. The first stage of work was the preparation of a database using Microsoft Excel containing an algorithm with individual sheets, such as "Patient", "Diagnostics", "Overview", "Diseases”, "Differentiation”, "Diagnosis", "Comparison”, "Calculations", "Planning”, "Printing”, and "Documentation" (Figure 1). "Patient" contained personal details, filled tooth chart, and diagram displaying progress of current treatment. "Diagnostics" allowed for a quick note of current teeth status. Proceeding through the sequence made the differentiation and comparison more precise. "Planning" included information from previous sheets and autogenerated treatment plan, which requires changes according to dentist's needs. Next the program, its usefulness and accuracy, has been validated by the designer during few years of work in a dental office and among dentists participating in the study.

Described algorithm has been invented by Paweł Łabno in 2010 and updated since then according to PubMed articles regarding specific topics used in the software. Revisions are made every six months by the author. Currently, the program is being used in author's every day dental practice.

The following groups were distinguished for the study: - Group 1:

- Stage 1: Dentists who did medical history, examination, diagnosis, treatment plan, documentation, treatment, and recommendations based on methods used.

- Stage 2: In the next stage of the study, the doctor was trained to operate the software. Then, during the next visit of the same patient, the doctor again performed comprehensive diagnostics and performed similar treatment, but this time using an algorithm.

- Group 2: dentists who did the interview, examination, diagnosis, treatment plan, documentation, treatment,

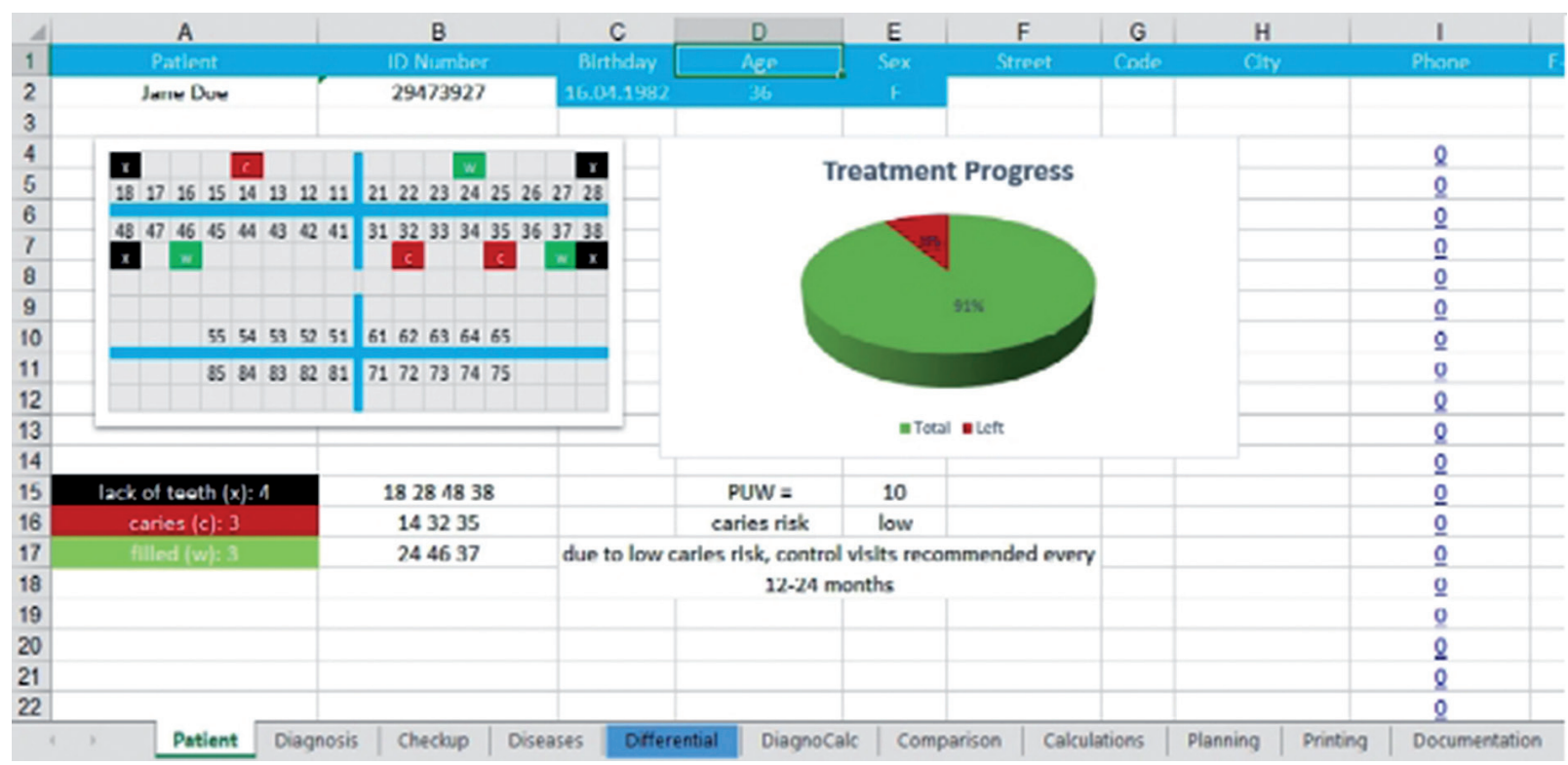

FIGURE 1. Example of the first page of diagnostic algorithm 
TABLE 1. Answers given by dentists in a questionnaire depending on gender $\left(\chi^{2}-\chi^{2}\right.$ Pearson, $\chi^{2}$ Fisher's test)

Question $\quad \boldsymbol{n} \quad \% \quad \boldsymbol{p}$-value

Q1: "Do you think that the algorithm used increases the accuracy of the interview?"

\begin{tabular}{l|c|c|c}
\hline No & 9 & 3.00 & \multirow{2}{*}{0.069} \\
\cline { 1 - 2 } Yes & 291 & 97.00 & \\
\hline
\end{tabular}

Q2: "Do you think that the algorithm used increases the accuracy of the examination?"

\begin{tabular}{c|c|c|c}
\hline No & 13 & 4.33 & \multirow{2}{*}{0.560} \\
\cline { 1 - 2 } Yes & 287 & 95.67 & \\
\hline
\end{tabular}

Q3:"Do you think that the algorithm used increases the possibility of making the right diagnosis?"

\begin{tabular}{l|c|c|c}
\hline No & 3 & 1.00 & \multirow{2}{*}{0.109} \\
\hline Yes & 297 & 99.00 & \\
\hline
\end{tabular}

Q4: "Do you think that the algorithm used improves the quality of treatment?"

\begin{tabular}{l|c|c|c}
\hline No & 12 & 4.00 & \multirow{2}{*}{0.331} \\
\hline Yes & 288 & 96.00 & \\
\hline
\end{tabular}

Q5: "Do you think that the algorithm used improves the quality of the documentation created?"

\begin{tabular}{|l|c|c|c}
\hline No & 4 & 1.33 & \multirow{2}{*}{0.282} \\
\cline { 1 - 2 } Yes & 296 & 98.67 & \\
\hline
\end{tabular}

Q6: "Do you think that the algorithm used facilitates the transfer of posttreatment recommendations?"

\begin{tabular}{l|c|c|c}
\hline No & 34 & 11.33 & \multirow{2}{*}{0.329} \\
\hline Yes & 266 & 88.67 & \\
\hline
\end{tabular}

Q7: "Do you think that the algorithm used increases the safety of the patient and the doctor?"

\begin{tabular}{l|c|c|c}
\hline No & 18 & 6.00 & \multirow{2}{*}{0.337} \\
\cline { 1 - 2 } Yes & 282 & 94.00 & \\
\hline
\end{tabular}

Q8: "Do you think that the algorithm used facilitates communication with the patient?"

\begin{tabular}{l|c|c|c}
\hline No & 27 & 9.00 & \multirow{2}{*}{0.987} \\
\cline { 1 - 2 } Yes & 273 & 91.00 & \\
\hline
\end{tabular}

Q9: "Do you think that the algorithm used increases the patient's awareness of his/her state of health and healing abilities?"

\begin{tabular}{l|c|c|c}
\hline No & 10 & 3.33 & \multirow{2}{*}{0.574} \\
\cline { 1 - 2 } Yes & 290 & 96.67 & \\
\hline
\end{tabular}

Q10: "Do you think that the algorithm used has improved the quality of your work?"

\begin{tabular}{c|c|c|c|}
\hline No & 9 & 3.00 & \multirow{2}{*}{0.450} \\
\cline { 1 - 2 } Yes & 291 & 97.00 & \\
\hline
\end{tabular}

Q11: "Do you think that the algorithm used is more convincing to your patients?"

\begin{tabular}{c|c|c|c|}
\hline No & 9 & 3.00 & \multirow{2}{*}{0.213} \\
\hline Yes & 291 & 97.00 & \\
\hline
\end{tabular}

and recommendations based on the developed algorithm.

At the end of the visit, doctors received questionnaires enabling a detailed assessment of both visits. The following issues were examined among doctors: assessment of whether the algorithm used increased the accuracy of interview, examination, possibility of making an accurate diagnosis, quality of treatment performed, quality of documentation created, post-treatment recommendations, patient and doctor safety, communication with the patient, patient's awareness of his health condition and therapeutic options, quality of the doctor's work, and convincing patients to continue their treatment.

By introducing a reduced assessment scale, the basic assumption was made (purpose of the visit) and the treatment used was initially depending on objective clinical verification of the doctor.

\section{STATISTICAL ANALYSIS}

The obtained test results were subjected to statistical analysis. For quantitative features, the following were calculated: value range ( $\min , \max )$, arithmetic average $(\mathrm{M})$, median (Me), standard deviation (SD), and 95\% confidence interval (95\% CI). The normality of distribution of continuous variables was assessed by KolmogorovSmirnov test. Due to skewed distribution of the measurable parameters tested and heterogeneity of variance, non-parametric tests assessing the significance of differences between the analyzed groups were used. Qualitative features were expressed in the form of numerical $(n)$ and percentage (\%) of distributions. Multiple regression model assessed the impact of analyzed features, including age, gender, medical need, and doctor's specialization on individual stages of research, such as interview, examination, and preparation of documentation. The following statistical evaluations were used in the study: $\chi^{2}-\chi^{2}$ Pearson's test, $\chi^{2}$ Fisher's test (Table 1), Kolmogorov-Smirnov test (Table 2), and Mann Whitney $U$ test (Table 3 ). The criterion of significance was $p<0.05$, indicating statistically significant relationships or differences (in the study, 5\% of inference error risk was assumed). Excel v. 2007 spreadsheet (Microsoft) and Statistica v. 10 (StatSoft, Inc.) were used for calculations.

\section{RESULTS}

Algorithm evaluation was made by dentists on a group of 300 treated patients, 156 women (52\%) and 144 men (48\%), with the average age of 34.13 years $(49.7 \%$ of respondents were under 30 years of age). The following procedures were evaluated and classified as operative: caries treatment, extractions, root canal treatment, and whitening. Procedures classified as other included follow-up visits, prosthetic consultations, orthodontic consultations, and surgical consultations. The group of doctors 
consisted of 3 with specialization (prosthetics, orthodontics, and maxillofacial surgery), who performed 86 procedures, and 3 non-specialized doctors, who performed 214 procedures.

For the majority of conducted examinations (88.67, 99\%), dentists stated that the algorithm used fulfilled their expectations regarding the interview and examination. The gender of patients did not have a statistically significant effect on the dentists' answers regarding the evaluation of algorithm used in the study (Table 1). Regarding specialization, only in question No. 7 (Q7): "Do you think that the algorithm used increases the safety of the patient and the doctor?", statistically significantly more often dentists without specialization indicated the answer as "no" ( $p<0.05)$. The remaining responses to the algorithm were not statistically significant in relation to the specialization of dental doctors (Table 2). Dentists examining younger patients, significantly more frequently provided negative answer to questions 1 (Q1) and 11 (Q11) $(p<0.05)$. The answers to other questions were not statistically significant in relation to the age of examined patients. The type of procedures performed did not have a statistically significant impact on doctors' opinions regarding the applied algorithm (Table 3).

The authors compared the time needed to complete an interview, examination, and treatment during 1 and 2 stage of the research for both operative and other procedures $(p<0.001)$ (Table 4$)$.

\section{DISCUSSION}

The development of modern technologies significantly affects the organization and operation of healthcare throughout the world. The way of obtaining, collecting, processing, and sending information about patient is definitely changing. However, due to such an intensive development of telemedicine, there is a justified fear that the progress will not be accompanied by an increase in the quality of services provided, due to lack of adequate system for controlling the devices or applied applications, assessing their effectiveness and safety $[14,15]$.

Critical theories about the number of scientific evidence-based publications, which require reading a huge amount of documents that are, at the same time, too expensive to obtain, were noted already by an $18^{\text {th }}$ century professor of medicine theory, Andrew Duncan. Also, modern reviews confirm that, despite the development of modern technologies enabling the use of evidence-based medicine, they are not always accompanied by an increase in the frequency of its use. Physicians, feeling overloaded with information and limited amount of ready-to-use updated algorithms, is another limitation. Supplementation of missing information should not be difficult; however, a study with Oxford's doctors showed that trainees do not read at all during the week, doctors during a specialization read 45-90 minutes
TABLE 2. Answers given by dentists depending on specialization (Kolmogorov-Smirnov test)

\begin{tabular}{|c|c|c|c|c|c|}
\hline \multirow{2}{*}{ Questio } & \multicolumn{2}{|c|}{ Non-specialist } & \multicolumn{2}{|c|}{ Specialist } & \multirow{2}{*}{$p$-value } \\
\hline & $n$ & $\%$ & $n$ & $\%$ & \\
\hline \multicolumn{6}{|l|}{ Q1 } \\
\hline $\mathrm{Nc}$ & 8 & 3.74 & 1 & 1.16 & \multirow{2}{*}{0.217} \\
\hline $\mathrm{Ye}$ & 206 & 96.26 & 85 & 98.84 & \\
\hline \multicolumn{6}{|l|}{ Q2 } \\
\hline No & 10 & 4.67 & 3 & 3.49 & \multirow{2}{*}{0.460} \\
\hline Ye & 204 & 95.33 & 83 & 96.51 & \\
\hline \multicolumn{6}{|l|}{ Q3 } \\
\hline No & 3 & 1.40 & 0 & 0.00 & \\
\hline Ye & 211 & 98.60 & 86 & 100.00 & \\
\hline
\end{tabular}

Q4

\begin{tabular}{|l|c|c|c|c|c}
\hline No & 12 & 5.61 & 0 & 0.00 & \multirow{2}{*}{-} \\
\cline { 1 - 4 } Yes & 202 & 94.39 & 86 & 100.00 &
\end{tabular}

Q5

\begin{tabular}{c|c|c|c|c|c}
\hline No & 4 & 1.87 & 0 & 0.00 & \multirow{2}{*}{ - } \\
\cline { 1 - 5 } Yes & 210 & 98.13 & 86 & 100.00 &
\end{tabular}

Q6

\begin{tabular}{|c|c|c|c|c|c|}
\hline No & 28 & 13.08 & 6 & 6.98 & \multirow{2}{*}{0.092} \\
\hline Yes & 186 & 86.92 & 80 & 93.02 & \\
\hline \multicolumn{6}{|c|}{27} \\
\hline No & 17 & 7.94 & 1 & 1.16 & \multirow{2}{*}{$<0.05$} \\
\hline Yes & 197 & 92.06 & 85 & 98.84 & \\
\hline
\end{tabular}

Q8

\begin{tabular}{l|c|c|c|c|c}
\hline No & 22 & 10.28 & 5 & 5.81 & \multirow{2}{*}{0.159} \\
\cline { 1 - 5 } Yes & 192 & 89.72 & 81 & 94.19 & \\
\hline
\end{tabular}

Q9

\begin{tabular}{|l|c|c|c|c|c}
\hline No & 8 & 3.74 & 2 & 2.33 & \multirow{2}{*}{0.416} \\
\cline { 1 - 4 } Yes & 206 & 96.26 & 84 & 97.67 & \\
\hline
\end{tabular}

010

\begin{tabular}{l|c|c|c|c|c}
\hline No & 8 & 3.74 & 1 & 1.16 & \multirow{2}{*}{0.217} \\
\cline { 1 - 5 } Yes & 206 & 96.26 & 85 & 98.84 & \\
\hline
\end{tabular}

011

\begin{tabular}{l|c|c|c|c|c}
\hline No & 9 & 4.21 & 0 & 0.00 & \multirow{2}{*}{-} \\
\cline { 1 - 5 } Yes & 205 & 95.79 & 86 & 100.00 & \\
\hline
\end{tabular}

a week, and specialists even less. One-third of the specialists did not read anything about their patients during a week of the study, while a part that were reading, spent more time on their way to the library and back than on actual reading $[16,17]$.

The Food and Drug Administration points out that both software and devices should be the subject of control of relevant organizations to assess not only the appropriate level of protection of sensitive medical data, such as health, 
TABLE 3. Type of procedures performed and dentists' assessment of the applied algorithm depending on type of procedure and age of patient (Mann-Whitney $U$ test)

\begin{tabular}{|c|c|c|c|c|c|c|c|c|c|c|}
\hline \multirow{2}{*}{ Question } & \multicolumn{2}{|c|}{ Other } & \multicolumn{2}{|c|}{ Operative } & \multirow{2}{*}{$p$-value } & \multicolumn{2}{|c|}{$\leq 31$ years old } & \multicolumn{2}{|c|}{$>31$ years old } & \multirow{2}{*}{$p$-value } \\
\hline & $n$ & $\%$ & $n$ & $\%$ & & $n$ & $\%$ & $n$ & $\%$ & \\
\hline \multicolumn{11}{|l|}{ Q1 } \\
\hline No & 2 & 2.47 & 7 & 3.20 & \multirow{2}{*}{0.544} & 8 & 5.03 & 1 & 0.71 & \multirow{2}{*}{$<0.05$} \\
\hline Yes & 79 & 97.53 & 212 & 96.80 & & 151 & 94.97 & 140 & 99.29 & \\
\hline \multicolumn{11}{|l|}{ Q2 } \\
\hline No & 1 & 1.23 & 12 & 5.48 & \multirow{2}{*}{0.092} & 6 & 3.77 & 7 & 4.96 & \multirow{2}{*}{0.411} \\
\hline Yes & 80 & 98.77 & 207 & 94.52 & & 153 & 96.23 & 134 & 95.04 & \\
\hline \multicolumn{11}{|l|}{ Q3 } \\
\hline No & 0 & 0.00 & 3 & 1.37 & \multirow{2}{*}{-} & 3 & 1.89 & 0 & 0.00 & \multirow{2}{*}{-} \\
\hline Yes & 81 & 100.00 & 216 & 98.63 & & 156 & 98.11 & 141 & 100.00 & \\
\hline \multicolumn{11}{|l|}{ Q4 } \\
\hline No & 3 & 3.70 & 9 & 4.11 & \multirow{2}{*}{0.586} & 8 & 5.03 & 4 & 2.84 & \multirow{2}{*}{0.252} \\
\hline Yes & 78 & 96.30 & 210 & 95.89 & & 151 & 94.97 & 137 & 97.16 & \\
\hline \multicolumn{11}{|l|}{ Q5 } \\
\hline No & 1 & 1.23 & 3 & 1.37 & \multirow{2}{*}{0.705} & 3 & 1.89 & 1 & 0.71 & \multirow{2}{*}{0.358} \\
\hline Yes & 80 & 98.77 & 216 & 98.63 & & 156 & 98.11 & 140 & 99.29 & \\
\hline \multicolumn{11}{|l|}{ Q6 } \\
\hline No & 9 & 11.11 & 25 & 11.42 & \multirow{2}{*}{0.562} & 20 & 12.58 & 14 & 9.93 & \multirow{2}{*}{0.470} \\
\hline Yes & 72 & 88.89 & 194 & 88.58 & & 139 & 87.42 & 127 & 90.07 & \\
\hline \multicolumn{11}{|l|}{ Q7 } \\
\hline No & 4 & 4.94 & 14 & 6.39 & 0127 & 10 & 6.29 & 8 & 5.67 & 0500 \\
\hline Yes & 77 & 95.06 & 205 & 93.61 & 0.431 & 149 & 93.71 & 133 & 94.33 & 0.509 \\
\hline Q8 & & & & & & & & & & \\
\hline No & 10 & 12.35 & 17 & 7.76 & 0157 & 13 & 8.18 & 14 & 9.93 & 596 \\
\hline Yes & 71 & 87.65 & 202 & 92.24 & $0.13 /$ & 146 & 91.82 & 127 & 90.07 & 0.390 \\
\hline Q9 & & & & & & & & & & \\
\hline No & 2 & 2.47 & 8 & 3.65 & 0464 & 6 & 3.77 & 4 & 2.84 & 0457 \\
\hline Yes & 79 & 97.53 & 211 & 96.35 & 0.404 & 153 & 96.23 & 137 & 97.16 & $0.4 J 2$ \\
\hline Q10 & & & & & & & & & & \\
\hline No & 1 & 1.23 & 8 & 3.65 & 0251 & 6 & 3.77 & 3 & 2.13 & 0314 \\
\hline Yes & 80 & 98.77 & 211 & 96.35 & 0.231 & 153 & 96.23 & 138 & 97.87 & 0.314 \\
\hline Q11 & & & & & & & & & & \\
\hline No & 2 & 2.47 & 7 & 3.20 & 0544 & 8 & 5.03 & 1 & 0.71 & \\
\hline Yes & 79 & 97.53 & 212 & 96.80 & 0.544 & 151 & 94.97 & 140 & 99.29 & $<0.05$ \\
\hline
\end{tabular}

photos, symptoms, test results, correctness of information provided, recommendations, methods of further treatment, and patients' management, but also the entire data processing, which affect the results presented by these devices or programs, e.g., algorithm, dependencies, equations, mathematical analysis methods, data sources, knowledge bases, information processing criteria, etc. [18].

The use of evidence-based medicine or dentistry, despite its many advantages, has some difficulties in its distribution. One of them is the limited number of clinically relevant publications, especially in dentistry, concerning the procedures performed by doctors. Another problem is the need of prepaid subscription of several magazines, translations, and search for clinically important articles. On the other hand, an excessive number of reports that contain different results regarding the same issue, such as case reports, case presentations, or expert views, lead to a situation, in which a doctor 
TABLE 4. Type of procedures performed, and time values assigned to particular stages of the research

\begin{tabular}{|c|c|c|c|c|c|c|c|}
\hline \multirow{2}{*}{ Procedure } & \multicolumn{3}{|c|}{ Other procedures } & \multicolumn{3}{|c|}{ Operative procedures } & \multirow{2}{*}{$p$-value } \\
\hline & $n$ & M & SD & $n$ & M & SD & \\
\hline Interview (1) & 81 & 22.79 & 15.90 & 219 & 13.11 & 14.79 & $<0.001$ \\
\hline Interview (2) & 81 & 105.02 & 11.78 & 219 & 105.47 & 10.81 & 0.8099 \\
\hline Examination (1) & 81 & 57.85 & 37.41 & 219 & 30.19 & 27.30 & $<0.001$ \\
\hline Examination (2) & 81 & 200.62 & 22.77 & 219 & 198.96 & 21.46 & 0.5568 \\
\hline Documentation (1) & 81 & 7.44 & 8.37 & 219 & 2.95 & 6.19 & $<0.001$ \\
\hline Documentation (2) & 81 & 0.00 & 0.00 & 219 & 0.00 & 0.00 & - \\
\hline
\end{tabular}

has his own opinion. Therefore, there is a necessity to increase organizational and financial effort to verify published investigations. However, finding the latest materials and treatments is still a problem because of the delay in publishing high-quality researches. Clinical trials with a randomized control groups are expensive and difficult to carry out, with long waiting time for the publication to be printed (minimum 6-8 months). In addition, only a small number of clinical cases in dentistry are life-threatening conditions for patients, which is why studies in this field of medicine are not critical $[19,20]$.

Evidence-based medicine increases the competence of people responsible for medical decisions in the office, clinic, hospital, or organization as well as improves the motivation of doctors, resulting in performing the treatment based on reliable and proven knowledge. Additionally, EBM helps the doctor to make the right choice regarding drugs or examination, facilitates the appropriate selection of medicines in a pharmacy for specific group of patients in order to obtain exact effect, or enables to determine which drugs should be reimbursed for a given disease in a given healthcare system. It makes it possible to distinguish between more and less reliable information, obtain clinically relevant information, and translate the language of scientific research into information that is understandable to patients. It is important that doctors, by being able to critically assess the originality of publications and the results obtained, depend less on inaccurate data, such as opinions or treatment methods used by other doctors or information provided by the pharmaceutical industry. Most doctors perform their treatments according to learned standards, of which they are convinced, and the results could be observed for years. Therefore, changing their work pattern is extremely difficult; it requires the need for a change, resulting from self-criticism, medical ethics, and the development of their own practice. This is also confirmed by the results of own research [21,22].

There is a great demand among both beginners and experienced dentists to provide proven and practical knowledge presented in an easily assimilated form, which can be the original electronic diagnostic algorithm. Doctors drew attention to its high value and the need for further development. However, a doctor who wants to use ready-made guidelines in everyday practice must correctly interpret the recommendations. First of all, the specialist must be aware whether the test results relate to a particular patient or a group of patients. An important limitation of most guidelines is that they refer to the "average" patient and rarely consider the coexistence of other diseases [23].

Despite the increasing scope of knowledge, doctors maintain medical documentation according to their many years of experience regarding only the extent and specialty of dentistry they represent. The number of dental medical publications is also increasing, facilitating doctor's decision making, but their credibility is limited due to the lack of documented literature. While the number of publications is constantly growing, doctors spend hardly any time with patients or spend less time progressing their knowledge. Therefore, there is a need to develop documentation to help the doctor to get the widest possible context of the patient's ailments, which at the same time will not be too difficult to implement or cause financial losses. Moreover, guidelines presented to physicians should facilitate decision making, must be reliable, understandable, practical, and their goal should aim at providing appropriate and effective assistance to the patient $[24,25]$.

Most of the currently developed programs for servicing dental offices have their own interview, examination, referral, treatment protocols, and the ability to create their own templates. The use of such software improves the quality of documentation prepared by doctors. However, from our point of view, it would be reasonable to extend the possibilities of programs for dental offices to include differentiation, diagnosis, presentation of disease's entities with similar symptoms as well as displaying articles containing current guidelines in accordance with the latest literature [26].

In this work, diagnostic and therapeutic activities were carried out on the basis of direct contact with patients of a medical clinic. Similar studies have been carried out by other authors, mainly based on the analysis of face and mouth photos sent via mobile phones, mobile applications, and e-mails as well as the simulation 
of clinical decisions using virtual patients. It is believed that the development of similar systems using distance learning and assistance in clinical decision making, should be supported by institutions and organizations and, in the opinion of other authors, should be free of charge [27-29].

The application of the electronic dental diagnostic algorithm increases the safety of both the doctor and patient during the entire treatment process by using current medical knowledge and maintaining correct medical documentation. The prepared program facilitates data collection and increases the accuracy of interviews and examinations, improves the correctness of diagnoses, reduces the time to prepare documentation, protects the doctor in legal terms, increases the quality of services performed, and improves communication between the doctor and patient. This approach increases the patient's awareness about own health and medical needs, leaving him convinced that he/she is under the care of a specialist doctor. Also, it positively affects the reception of a doctor and increases patient's confidence if sees a commitment and individual approach of the doctor by searching information in the Internet about the patient's' health. The presented procedure increases the level of knowledge among doctors [30].

\section{CONCLUSIONS}

The application of the proposed diagnostic algorithm is positively received by doctors. In the opinion of dentists using the proposed algorithm, the biggest advantage of the program was the speed of creating detailed patients' documentation. Most dentists considered work using the algorithm as facilitating communication with the patient and increasing his participation in the treatment process. The solutions resulting from the application of the algorithm allow improving individual stages of the patient's dental visit. A small percentage of dentists negatively assessed the proposed procedure. The most frequently mentioned disadvantage of the proposed program was the extension of time needed to perform the test in accordance with the algorithm. The conducted research indicates the need for a holistic approach to the patient and raising awareness of the impact of systemic diseases on the state of oral health.

\section{CONFLICT OF INTEREST}

The authors declare no potential conflicts of interest with respect to the research, authorship, and/or publication of this article.

\section{References}

1. Guyatt G, Cook D, Haynes B. Evidence based medicine has come a long way. BMJ 2004; 329: 990-991.
2. Elstein AS. On the origins and development of evidence-based medicine and medical decision making. Inflamm Res 2004; 53 Suppl 2: S184-189.

3. Sackett D. Evidence-based medicine : how to practice and teach EBM. J Clin Pathol 2000. doi: 10.1016/S1031-170X(97)80036-0.

4. Murthy L, Shepperd S, Clarke MJ, et al. Interventions to improve the use of systematic reviews in decision-making by health system managers, policy makers and clinicians. Cochrane Database Syst Rev 2012; 9: CD009401.

5. Cześnikiewicz-Guzik MJ, Osiewicz MA, Dohnal T, Loster JE, Loster BW. Stomatologia oparta na faktach - narzędzie, które powinniśmy stosować w praktyce klinicznej z oficjalną, polską wersją “Deklaracji CONSORT 2010". J Stomatol 2014; 67: 728-732.

6. Rosenberg WM, Deeks J, Lusher A, Snowball R, Dooley G, Sackett D. Improving searching skills and evidence retrieval. J R Coll Physicians Lond 1998; 32: 557-563.

7. Funkhouser E, Agee BS, Gordan VV, et al. Use of online sources of information by dental practitioners: Findings from the Dental Practice-Based Research Network. J Public Health Dent 2014; 74: 71-79.

8. Strother EA, Lancaster DM, Gardiner J. Information needs of practicing dentists. Bull Med Libr Assoc 1986; 74: 227-230.

9. Fiander M, McGowan J, Grad R, et al.; Cochrane Effective Practice and Organisation of Care Group. Interventions to increase the use of electronic health information by healthcare practitioners to improve clinical practice and patient outcomes. Cochrane Database Syst Rev 2015; 2015 : CD004749.

10. Estai M, Kanagasingam Y, Xiao D, et al. A proof-of-concept evaluation of a cloud-based store-and-forward telemedicine app for screening for oral diseases. J Telemed Telecare 2016; 22: 319-325.

11. Rawlins MD. Evidence-based medicine. Medicine 2018; 46: 388-392.

12. Hollis W, Darnell LA, Hottel TL. Computer assisted learning: a new paradigm in dental education. J Tenn Dent Assoc Fall 2011; 91: 14-18.

13. Sam FE, Bonnick AM. Office computer systems for the dental office. Dent Clin North Am 2011; 55: 549-557.

14. Casebeer L, Brown J, Roepke N, et al. Evidence-based choices of physicians: a comparative analysis of physicians participating in Internet CME and non-participants. BMC Med Educ 2010. doi: 10.1186/1472-6920-10-42.

15. Schleyer TK. Clinical decision-making and the Internet. J Am Coll Dent Summer 1999; 66: 29-39.

16. Hojat M, Nasca TJ, Erdmann JB, Frisby AJ, Veloski JJ, Gonnella JS. An operational measure of physician lifelong learning: Its development, components and preliminary psychometric data. Med Teach 2003; 25: 433-437.

17. Jacob RF, Carr AB. Hierarchy of research design used to categorize the "strength of evidence" in answering clinical dental questions. J Prosthet Dent 2000; 83: 137-152.

18. Epling J, Smucny J, Patil A, Tudiver F. Teaching evidence-based medicine skills through a residency - developed guideline. Fam Med 2002; 34: 646-648.

19. Guyatt GH, Oxman AD, Kunz R, Vist GE, Falck-Ytter Y, Schünemann HJ; GRADE Working Group. What is "quality of evidence" and why is it important to clinicians? BMJ 2008; 336: 995-998.

20. Fozi K, Teng CL, Krishnan R, Shajahan Y. A study of clinical questions in primary care. Med J Malaysia 2000; 55: 486-492.

21. Horsley T, O’Neill J, McGowan JL, Perrier L, Kane G, Campbell C. Interventions to improve question formulation in professional practice and self-directed learning. Cochrane Database Syst Rev 2010; 5: CD007335.

22. Delrose DC, Steinberg RW. The clinical significance of the digital patient record. J Am Dent Assoc 2000; 131 Suppl: 57S-60S.

23. Gottschalk A, Flocke SA. Time spent in face-to-face patient care and work outside the examination room. Ann Fam Med 2005; 3: 488-493. 
24. Thom DH, Haugen J, Sommers PS, Lovett P. Description and evaluation of an EBM curriculum using a block rotation. BMC Med Educ 2004; 4: 19.

25. Currell R, Urquhart C, Wainwright P, Lewis R. Telemedicine versus face to face patient care: effects on professional practice and health care outcomes. Cochrane Database Syst Rev 2000; 2: CD002098.

26. Lin CT, Albertson GA, Schilling LM, et al. Is patients' perception of time spent with the physician a determinant of ambulatory patient satisfaction? Arch Intern Med 2001; 161: 1437-1442.

27. Anderson JD. Need for evidence-based practice in prosthodontics. J Prosthet Dent 2000; 83: 58-65.

28. Benn DK, Clark TD, Dankel DD, Kostewicz SH. Practical approach to evidence-based management of caries. J Am Coll Dent Spring 1999; 66: 27-35.

29. Łabno P, Łabno A, Chałas R. Telemedicine applications in modern medicine, the possibilities and limitations. Eur J Med Tech 2017; 4: 37-41.

30. Eysenbach G, Diepgen TL. The role of e-health and consumer health informatics for evidence-based patient choice in the 21st century. Clin Dermatol 2001; 19: 11-17. 